\title{
Retraction Note: Structure of plain granular rock mass based on motion sensor and movement evaluation of dancers
}

\author{
Jing Zhang ${ }^{1}$
}

Published online: 3 November 2021

C) Saudi Society for Geosciences 2021

Retraction Note: Arabian Journal of Geosciences (2021) 14: 1521

https://doi.org/10.1007/s12517-021-07936-0

The Editor-in-Chief and the Publisher have retracted this article because the content of this article is nonsensical. The peer review process was not carried out in accordance with the Publisher's peer review policy. The author has not responded to correspondence regarding this retraction.

The original article can be found online at https://doi.org/10.1007/ s12517-021-07936-0.

Jing Zhang

1 Shanxi Vocational College of Art, Taiyuan, Shanxi, China 